\title{
Prevention of Incisional Hernia after Open Hepato-Pancreato-Biliary Surgery: A Systematic Review
}

\author{
Robert Memba ${ }^{a, b} \quad$ Olga Morató ${ }^{a} \quad$ Laia Estalella ${ }^{a, b} \quad$ Mihai C. Pavela,b \\ Erik Llàcer-Millán ${ }^{\mathrm{a}, \mathrm{b}}$ Mar Achalandabaso ${ }^{\mathrm{a}, \mathrm{b}}$ Elisabet Julià ${ }^{\mathrm{a}}$ Erlinda Padilla $^{\mathrm{c}}$ \\ Carles Olona ${ }^{b, c}$ Donal O'Connord Rosa Jorba ${ }^{a, b}$ \\ ${ }^{a}$ Hepato-Pancreato-Biliary Unit, General Surgery Department, University Hospital of Tarragona Joan XXIII, \\ Tarragona, Spain; 'b School of Medicine, Rovira i Virgili University, Reus, Spain; 'A Abdominal Wall Surgery Unit, \\ General Surgery Department, University Hospital of Tarragona Joan XXIII, Tarragona, Spain; ${ }^{\text {dDepartment of }}$ \\ Surgery, School of Medicine, Trinity College Dublin, College Green, Dublin, Ireland
}

\section{Keywords}

Incisional hernia $\cdot$ Prophylactic mesh $\cdot$ Hepato-pancreato-

biliary surgery $\cdot$ Subcostal incision $\cdot$ Mesh reinforcement

\begin{abstract}
Introduction: Most hepato-pancreato-biliary (HPB) procedures are still performed through open approach. Incisional hernia $(\mathrm{IH})$ is one of the most common complications after open surgery. To date, published data on IH after HPB surgery are scarce; therefore, the aim of this study was to assess the current evidence regarding incidence, risk factors, and prevention. Methods: Medline/PubMed (1946-2020), EMBASE (1947-2020), and the Cochrane library (1995-2020) were searched for studies on IH in open HPB surgery. Animal studies, editorials, letters, reviews, comments, short case series and liver transplant, laparoscopic, or robotic procedures were excluded. The protocol was registered with PROSPERO (CRD42020163296). Results: A total of 5,079 articles were retrieved. Eight studies were finally included for the analysis. The incidence of IH after HPB surgery ranges from $7.7 \%$ to $38.8 \%$. The identified risk factors were body mass index, surgical site infection, ascites, Mercedes or reversed T incisions, and previous $\mathrm{IH}$. Prophylactic mesh might be safe and effec-
\end{abstract}

(C) 2021 S. Karger AG, Basel

www.karger.com/dsu tive. Conclusions: IH after open HPB surgery is still an important matter. Some of the risk factors are specific for the HPB operations and the incision type should be carefully considered. Randomized controlled trials are required to confirm the role of prophylactic mesh after HPB operations.

(c) 2021 S. Karger AG, Basel

\section{Introduction}

The use of minimally invasive surgery (MIS) for hepatobiliary and pancreatic operations is still not widely adopted. While laparoscopic cholecystectomy has been standard-of-care for nearly 3 decades, MIS has only become common for a minority of specific hepato-pancreato-biliary (HPB) procedures such as distal pancreatectomy or minor hepatectomies. Overall use of MIS approach for HPB surgery remains less than $10 \%[1,2]$. A major limitation for the expansion of MIS is the technically complex nature of liver and pancreas resections with steep learning curves even for the open approach. Robotic surgery has the potential to overcome some of these disadvantages, but the specific devices needed to facilitate laparoscopic or robotic HPB procedures, for example,

\footnotetext{
Karger"
}

Correspondence to:

Robert Memba,rmembai.hj23.ics@gencat.cat 
complex parenchymal liver resection is still evolving [ 1 , 3]. Concerning pancreatic surgery, despite the favourable outcomes for MIS distal pancreatectomy [4, 5], laparoscopic, or robotic pancreatoduodenectomies are performed in only a limited number of high-volume centres [6-8].

Abdominal wall complications are a clear disadvantage of open surgery compared to MIS and have particular impact in terms of quality of life, body image, and healthcare utilization costs. Incisional hernia ( $\mathrm{IH})$, wound dehiscence, and surgical site infection (SSI) are all more commonly associated to open HPB surgery $[1,2,9]$.

$\mathrm{IH}$ is one of the most common complications after open surgery. The European Hernia Society (EHS) [10] published a consensus classification that has proven its use to compare different hernia studies and to analyse the differences according to the type of incision. IH after HPB procedures is commonly classified as lateral subcostal (L1). The incidence of $\mathrm{IH}$ in the lateral incisions commonly used for HPB surgery is lower than in midline laparotomies. However, surgical repair of lateral IH can be challenging due to the proximity of bone limits and intercostal nerves. In addition, lateral IH has high recurrence rates [11-13]. The true incidence of $\mathrm{IH}$, while widely reported after liver transplantation (LT) [14-17], it is not been established for other HPB procedures [16, 18]. Overall risk factors such as wound infection and dehiscence, previous hernia repair, immunosuppression, type of incision, and obesity are well described [16, 18-23] although no consensus has been published regarding additional specific risk factors for IH development in HPB procedures other than LT $[14,15]$. Conversely, some published reviews suggest a benefit of prophylactic mesh placement in terms of IH risk reduction for midline laparotomies in high-risk patients while only few reviews have assessed the evidence in other types of laparotomies [24-26].

To date, published data on IH after HPB surgery are scarce. Therefore, the aims of this review were to examine the true incidence and the risk factors for $\mathrm{IH}$ after open HPB surgery, the differences according to the type of incision and to evaluate the potential benefit and safety of prophylactic mesh in these patients.

\section{Methods}

Systematic Literature Search

A systematic electronic literature search was developed with a medical librarian to identify studies on IH in open HPB surgery using the following databases: Medline/PubMed (1946-2020),
EMBASE (1947-2020), and the Cochrane library (Cochrane Database of Systematic Reviews [1995-2020], Cochrane Central Register of Controlled Trials [1996-2020], and Cochrane Clinical Answers [2012-2020]). Online lists of relevant conference proceedings were also searched. The search strategy was devised to identify articles relating to any abdominal wall complication in non-midline incisions and in liver, pancreas, or biliary procedures (online suppl. material 1 [for all online suppl. material, see www. karger.com/doi/10.1159/000521169] for complete search strategy including MeSH terms and the CoCoPop, PEO, and PICOS models used to devise the literature search).

Two authors independently performed the search, title, and abstract screening (R.M. and O.M.), and any conflicts were resolved by an independent $3 \mathrm{rd}$ author (R.S.). Where a study was considered potentially relevant, a full copy of the publication was obtained for further review. The reference lists of the included studies were hand-searched for further relevant potential studies. The work has been reported in line with [27] Preferred Reporting Items for Systematic Reviews and Meta-Analyses (PRISMA) and AMSTAR [28] (Assessing the methodological quality of systematic reviews) Guidelines. PRISMA checklist is provided as online supplementary material 2 . This study was prospectively registered with thePROSPEROdatabase(Registration numberCRD42020163296). The search was last performed on 31 March 2020.

\section{Selection Criteria}

Randomized controlled trials (RCTs), including cluster RCTs, controlled (non-randomized) clinical trials or cluster trials, controlled before-after studies, prospective and retrospective comparative cohort studies, and case-control or nested case-control studies were included if they reported on the incidence, risk factors, or methods to prevent IH after open HPB surgery. No time or language restrictions were applied. Review articles, animal studies, editorials, letters, comments, and case series with $<5$ patients were excluded. Studies investigating IH in LT recipients, laparoscopic, or robotic procedures were also excluded.

\section{Study Outcome Measures and Quality Assessment}

The primary outcome measures sought were the true incidence, the risk factors and the potential benefit and safety of prophylactic mesh reinforcement to avoid IH after open HPB surgery. The secondary outcome measure was the difference according to the type of incision and closure method.

Methodological quality and standard of outcome reporting within included studies were assessed independently by 2 authors (R.M. and O.M.) using the Newcastle-Ottawa score (NOS) (score range 0-9 for non-randomized controlled studies [29]).

\section{Results}

\section{Study Selection}

The search yielded 5,079 titles. After title and abstract screening, 8 studies reporting outcomes in 3,717 patients were ultimately included in the systematic review qualitative analysis (see Fig. 1 for PRISMA flow diagram). The characteristics of the included studies are summarized in Tables 1 and 2. The retrieved studies were not sufficient- 


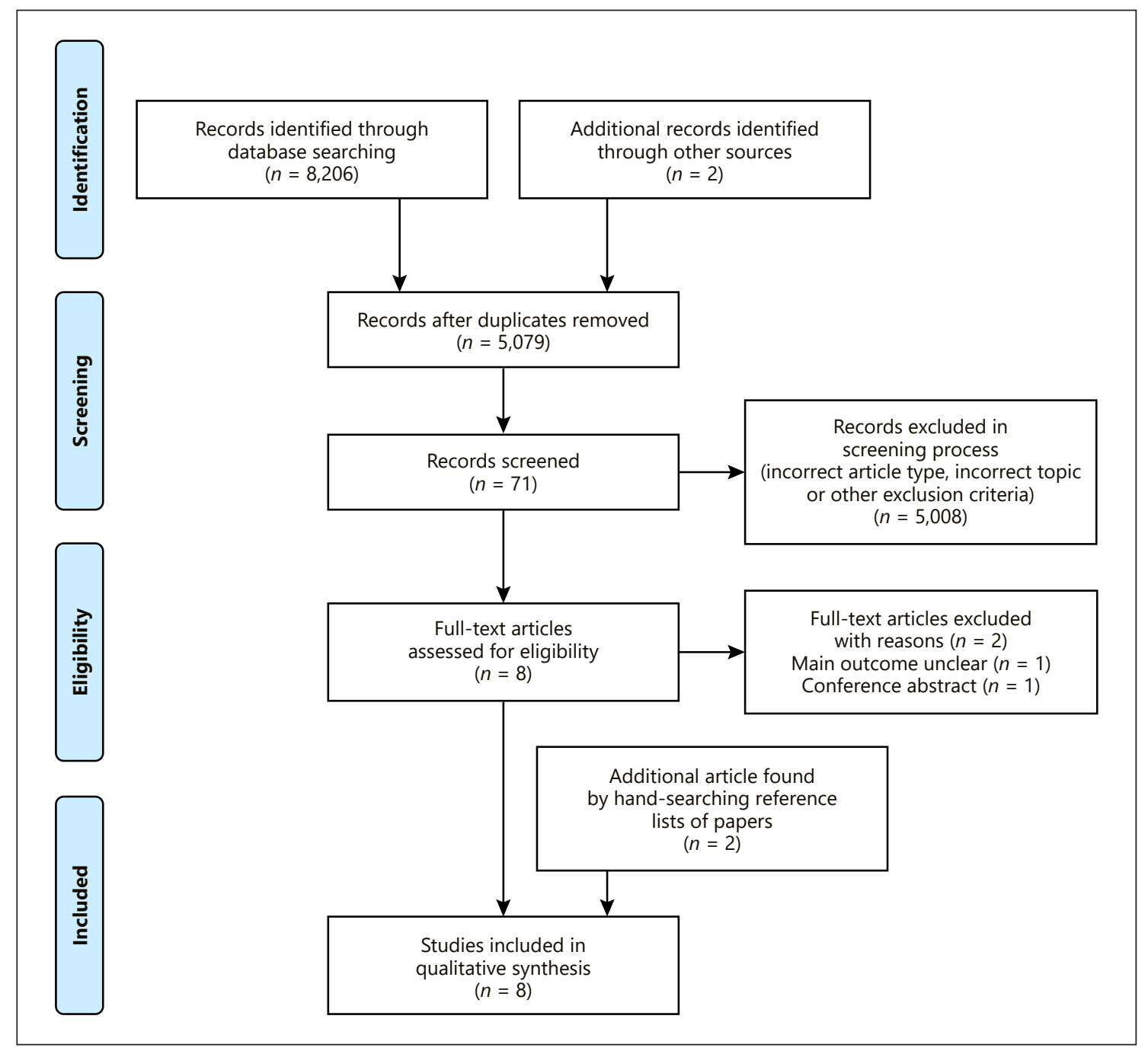

Fig. 1. PRISMA flow diagram for study selection.

ly comparable in terms of design and underlying clinical question so a quantitative meta-analysis was not feasible; therefore, a qualitative assessment and narrative synthesis were performed.

\section{Summary of Studies Included}

Most of the selected studies were from European countries with 2 from Japan, and one from the USA. All the studies were published within the last 15 years and 6 out of 8 within the last 5 years. The median NOS was 7 (range 6-9) indicating moderate to high quality. No RCTs have been published. Most studies were retrospective (6 out of 8 ), with only 2 based on a prospective cohort and also only 2 comparative studies [30,31]. The average sample size was 465 patients $(115-1,426)$ and the study periods ranged from 1991 to 2017. Most studies shared as primary variable the incidence of $\mathrm{IH}$ and the assessment of the risk factors for IH development, whilst some others analysed the difference in the incidence according to the type of incision or to the use of prophylactic mesh (Table 1).

\section{Incidence of IH in HPB Surgery}

All the selected articles assessed the incidence of IH. Firstly, D’Angelica et al. [32], Togo et al. [33], Kayashima et al. [34], Arslan et al. [35], and Nilsson et al. [36] analysed liver resections. Whilst D'Angelica et al. [32], Togo et al. [33], and Arslan et al. [35] included all hepatectomies, Kayashima et al. [34] focused on resections for hepatocellular carcinoma in cirrhotic patients, and Nilsson et al. [36] included only colorectal metastases. Secondly, 
Table 1. Summary of included studies

\begin{tabular}{|c|c|c|c|c|c|c|}
\hline \multirow{2}{*}{$\begin{array}{l}\text { Author } \\
\text { D'Angelica et al. } \\
\text { [32] }\end{array}$} & \multirow{2}{*}{$\begin{array}{l}\text { Country } \\
\text { USA }\end{array}$} & \multirow{2}{*}{$\begin{array}{l}\text { Study design } \\
\text { Retrospective comparative } \\
\text { (prospective maintained } \\
\text { database) }\end{array}$} & \multirow{2}{*}{$N$} & \multicolumn{2}{|c|}{ Study interval Main outcome } & \multirow{2}{*}{$\begin{array}{l}\text { NOS } \\
6 \\
6 \\
\text { (moderate) }\end{array}$} \\
\hline & & & & 1991-2001 & $\begin{array}{l}\text { Analyse difference regarding early and late IH } \\
\text { complications between Mercedes incision and ERSC } \\
\text { after liver resections }\end{array}$ & \\
\hline Togo et al. [33] & Japan & Retrospective comparative & 626 & 1991-2006 & $\begin{array}{l}\text { Analyse risk factors of } \mathrm{IH} \text { and the difference between } \\
\text { type of incisions after partial hepatectomy }\end{array}$ & 7 (high) \\
\hline $\begin{array}{l}\text { Kayashima et al. } \\
\text { [34] }\end{array}$ & Japan & Retrospective observational & 192 & 2009-2013 & $\begin{array}{l}\text { Incidence and risk factors of IH after hepatectomy for } \\
\text { HCCA in cirrhotic patients }\end{array}$ & 9 (high) \\
\hline Nilsson et al. [36] & Sweden & Retrospective observational & 256 & $2010-2013$ & $\begin{array}{l}\text { Incidence, location and risk factors of IH after open } \\
\text { hepatectomy for colorectal metastases }\end{array}$ & 8 (high) \\
\hline $\begin{array}{l}\text { Blazquez } \\
\text { Hernando et al. } \\
{[30]}\end{array}$ & Spain & $\begin{array}{l}\text { Prospective comparative } \\
\text { cohort }\end{array}$ & $\begin{array}{l}115 \\
\text { Controls (57) } \\
\text { Mesh (58) }\end{array}$ & $2009-2013$ & $\begin{array}{l}\text { Development of IH (efficacy) and safety (SSI, seroma, } \\
\text { mesh rejection, other complications) of prophylactic } \\
\text { mesh) in elective subcostal incisions }\end{array}$ & 8 (high) \\
\hline Arslan et al. [35] & Turkey & Prospective observational & 165 & $2007-2014$ & $\begin{array}{l}\text { Determine short and long-term wound-related } \\
\text { complications, incidence of } \mathrm{IH} \text { and risk factors for } \mathrm{IH} \\
\text { after hepatectomies }\end{array}$ & 7 (high) \\
\hline $\begin{array}{l}\text { Chen-Xu et al. } \\
\text { [18] }\end{array}$ & Portugal & Observational retrospective & 654 & 2010-2016 & $\begin{array}{l}\text { Evaluation of incidence and risk factors of IH in HPB } \\
\text { surgery }\end{array}$ & 7 (high) \\
\hline $\begin{array}{l}\text { Bravo-Salva et al. } \\
\text { [31] }\end{array}$ & Spain & Retrospective comparative & $\begin{array}{l}283 \\
\text { Suture (203) } \\
\text { Mesh (80) }\end{array}$ & $2011-2017$ & $\begin{array}{l}\text { Incidence of IH and efficacy of prevention with } \\
\text { prophylactic mesh in emergency subcostal incisions } \\
\text { and risk factors of IH }\end{array}$ & 7 (high) \\
\hline
\end{tabular}

ERSC, Right subcostal incision with vertical midline extension; HCCA, Hepatocellular carcinoma.

whilst Chen-Xu et al. [18] evaluated all open HPB procedures, Blazquez Hernando et al. [30] and Bravo-Salva et al. [31] included subcostal laparotomies (the first one for elective and the second for emergency surgeries). Most elective subcostal laparotomies were performed for HPB procedures, $81 \%$ according to Blazquez Hernando et al. [30] and $87 \%$ according to Bravo-Salva et al. [31] Notably, the exclusion criteria were heterogeneous among the selected studies. Moreover, the follow-up was also significantly different, ranging from a minimum of 6 months up to 168 months. Therefore, as the populations are not readily comparable, an accurate global incidence is not presented in this review. The estimated incidence of $\mathrm{IH}$ after HPB surgery might range from $7.7 \%$ to $38.8 \%$ (Table 2).

\section{Risk Factors for IH Development in HPB Surgery}

Both univariate and multivariate analysis were carried out in most of the studies to analyse potential risk factors. The risk for each potential factor was expressed as odds ratio (OR), hazard ratio (HR), or adjusted relative risk (ARR). Significance level $p<0.05$ was considered statistically relevant, corresponding to a confidence interval (CI) of $95 \%$. Table 2 summarises only the risk factors identi- fied in the multivariate analysis. Worth noting that Blazquez Hernando et al. [30] were the only researchers who did not analyse the risk factors. In contrast, BravoSalva et al. [31] identified SSI (4.905 HR, CI: 2.116-11.37, $p<0.001)$, previous hernia repair $(2.86 \mathrm{HR}, \mathrm{CI}: 1.24-6.61$, $p=0.014)$, and perioperative or postoperative shock (2.64 HR, CI: $1.01-6.93, p=0.048$ ) as significant risk factors in the multivariate analysis. Presenting the 3 risk factors meant a 99.5\% (95.0-99.9) probability of developing an $\mathrm{IH}$, whilst having none reduced the probability to $13 \%$ (7.76-18.7). Chen-Xu et al. [18] published the sole study also performing a multivariate model regression to assess IH risk factors after pancreatic surgery. SSI ( $6.698 \mathrm{HR}, \mathrm{CI}$ : 2.116-21.199, $p=0.001$ ), superficial wound dehiscence (26.402 HR, CI: $4.114-160.43, p=0.001)$, height $>167.5$ cm (4.835 HR, CI: $1.181-19.798, p=0.028)$, and subcutaneous fat thickness $>23.3 \mathrm{~mm}$ (3.692 HR, CI: $1.080-$ $12.621, p=0.037)$ were determined as risk factors of $\mathrm{IH}$ after pancreatic surgery. Perirenal fat thickness $>14.7 \mathrm{~mm}$ (2.251 HR, CI: $1.028-4.931, p=0.043)$ and body mass in$\operatorname{dex}(\mathrm{BMI})>26 \mathrm{~kg} / \mathrm{m}^{2}$ (2.694 HR, CI: 1.063-6.824, $p=$ 0.037 ) were the risk factors identified after hepatobiliary procedures. The 4 risk factors identified in the multivariate regression model by D'Angelica et al. [32] were inci- 


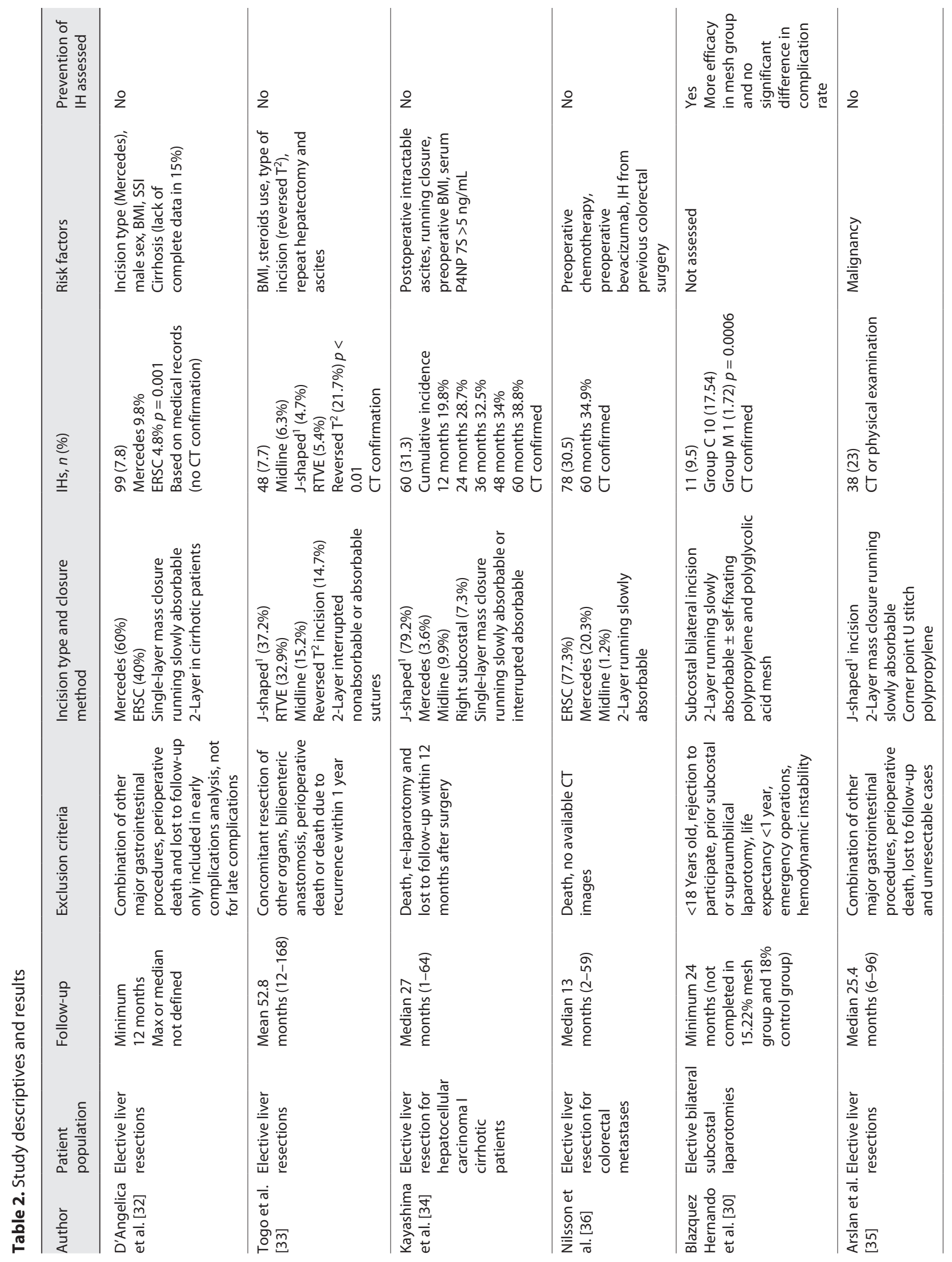




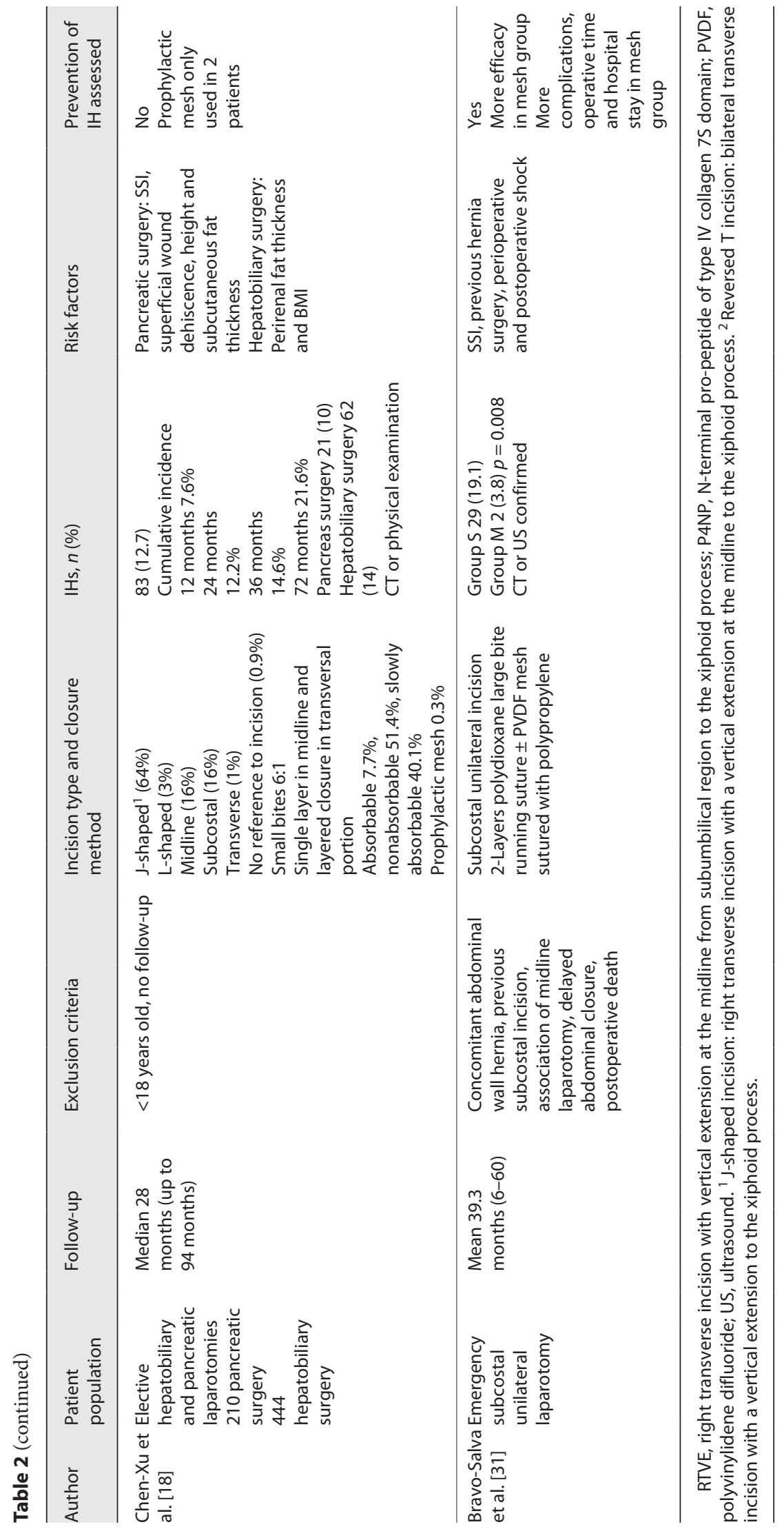


Table 3. Risk factors of IH in hepatobiliary and pancreatic surgery

\begin{tabular}{ll}
\hline Risk factors & Studies, $n$ \\
\hline BMI & $* * * *$ \\
SSI & $* * *$ \\
Ascites/cirrhosis & $* * *$ \\
Incision type (Mercedes or reversed T) & $* *$ \\
Previous hernia surgery or IH from colorectal surgery & $* *$ \\
Gender (male) & $*$ \\
Steroids use & $*$ \\
Repeat hepatectomy & $*$ \\
Running closure & $*$ \\
P4NP & $*$ \\
Chemotherapy & $*$ \\
Bevacizumab & $*$ \\
Superficial wound dehiscence & $*$ \\
Height & $*$ \\
Subcutaneous fat thickness & $*$ \\
Perirenal fat thickness & $*$ \\
Perioperative or postoperative shock & $*$ \\
Malignancy & $*$ \\
\hline
\end{tabular}

P4NP, N-terminal pro-peptide of type IV collagen 7S domain.

sion type (Mercedes type) (2.1 OR, CI: 1.3-3.4, $p=0.003$ ), male sex (1.6 OR, CI: $1.0-2.6, p=0.04)$, BMI (1.07 OR, CI: $1.03-1.11, p<0.001)$, and SSI (2.3 OR, CI: $1.2-4.2$, $p=0.01)$. Cirrhosis was also identified in this multivariate analysis ( $81 \%$ vs. $19 \%, p=0.01)$. The multivariate analysis by Kayashima et al. [34] for hepatectomies in cirrhotic patients identified intractable ascites (24.83 OR, CI: 3.78 $500.93, p=0.0003$ ), abdominal wall closure by a singlelayer mass closure with a continuous running suture (4.59 OR, CI: 1.33-20.77, $p=0.0143)$, preoperative $\mathrm{BMI}>25$ $\mathrm{kg} / \mathrm{m}^{2}$ (3.36 OR, CI: $\left.1.53-7.59, p=0.0025\right)$, and preoperative serum $\mathrm{N}$-terminal pro-peptide of type IV collagen 7S domain (P4NP 7S) levels $>5$ ng/mL (3.13 OR, CI: 1.16$9.12, p=0.0234)$. The multivariate analysis by Nilsson et al. [36] in hepatectomies for colorectal metastases were preoperative chemotherapy $>6$ cycles $(2.12 \mathrm{HR}, \mathrm{CI}: 1.14-$ $3.94, p=0.017)$, preoperative bevacizumab $(3.63 \mathrm{HR}, \mathrm{CI}$ : $1.86-7.08, p<0.0001)$, and previous IH (3.50 HR, 1.98$6.18, p<0.0001)$. Arslan et al. [35] identified malignancy as the only risk factor in the multivariate analysis $(2.12$ HR, CI: $1.07-4.18, p=0.03)$. Finally, according to Togo et al. [33], the multivariate regression model showed the following risk factors: reversed T incision (4.775 ARR, CI: 2.313-9.857, $p<0.0001$ ), ascites (4.373 ARR, CI: $1.590-$ $12.029, p=0.0043)$, BMI $>25 \mathrm{~kg} / \mathrm{m}^{2}(4.573$ ARR, CI: 2.279-9.173, $p<0.0001$ ), repeat hepatectomy (4.081 ARR, CI: $1.774-9.388, p=0.0009)$, and steroids use (48.845
ARR, CI: 5.413-440.797, $p=0.0005)$. Table 3 shows the common risk factors identified exclusively in the multivariate analysis of the selected studies. Even though the different studies analysed different risk factors and most did not coincide, the risk factors identified in more than one publication were BMI, SSI, ascites, incision type, and previous $\mathrm{IH}$.

\section{Prevention of IH in HPB Surgery}

Bravo-Salva et al. [31] and Blazquez Hernando et al. [30] published the only 2 comparative studies assessing the prevention of IH. Blazquez Hernando et al. [30] compared prospectively 2 groups of elective patients undergoing bilateral subcostal laparotomies (mesh group and control). There was a significant difference between the 2 groups regarding the $\mathrm{IH}$ incidence $(17.54 \%$ vs. $1.72 \%, p=$ 0.0006), with no differences in terms of complications. Similarly, Bravo-Salva et al. [31] conducted a retrospective comparison between 2 groups of emergency unilateral subcostal laparotomies (mesh group and control). No long-term complications such as mesh removal, chronic infection, or chronic pain occurred in mesh group and the incidence of IH was lower (19.1\% vs. $3.8 \%$, $p=0.008)$. Preoperative variables were significantly worse in mesh group: Preoperative shock $(26.5 \%$ vs. $40.0 \%, p=$ $0.039)$, vasoactive drugs treatment $(25.1 \%$ vs. $40.0 \%, p=$ $0.020)$, and rate of intensive care unit admission (42.5\% vs. $31.4 \%, p=0.018)$. By contrast, the degree of contamination was lower in the mesh group $(51.7 \%$ vs. $70 \%, p=$ 0.008). However, this fact did not have an impact on SSI or skin dehiscence, as differences were not detected amongst groups. Therefore, according to both studies, mesh reinforcement appears to be effective and safe to prevent IH in elective and emergency subcostal laparotomies.

\section{Differences According to Type of Incision and Closure Method}

The secondary outcome of our review was to identify the best incision type and closure method. On the one hand, both D'Angelica et al. [32] and Togo et al. [33] considered the differences in the incidence of IH according to the type of incision as part of their main outcome. On the other hand, Kayashima et al. [34], Nilsson et al. [36], and Chen-Xu et al. [18], also registered the incision type, however just as another variable. D'Angelica et al. [32] found a twofold higher rate of $\mathrm{IH}$ in Mercedes incision when compared to right subcostal incision with vertical midline extension (ERSC) after liver resections (9.8\% vs. $4.8 \%, p=0.001)$. Togo et al. [33] compared right trans-
12

Dig Surg 2022;39:6-16 DOI: $10.1159 / 000521169$
Memba et al. 
verse incision with vertical extension at the midline from subumbilical region to the xiphoid process, J-shaped incision (right transverse incision with a vertical extension at the midline to the xiphoid process), and reversed $\mathrm{T}$ incision (bilateral transverse incision with a vertical extension to the xiphoid process) in hepatectomies. According to logistic analysis of this study, when the reversed $\mathrm{T}$ incision was performed, the risk of IH increased by 4.775 times (midline $6.3 \%$ vs. J-shaped $4.7 \%$ vs. right transverse incision with vertical extension at the midline from subumbilical region to the xiphoid process $5.4 \%$ vs. reversed T 21.7\%, $p<0.01$ ). On the contrary, Kayashima et al. [34] did not find significant differences when comparing J-shaped to midline, right subcostal or Mercedes type incisions (33.6\% vs. $15.8 \%$ vs. $15.8 \%$ vs. $15.8 \%, p=$ 0.2776). No association between Mercedes and ERSC and $\mathrm{IH}$ incidence was found by Nilsson et al. [36] either ( $30.3 \%$ vs. $30.7 \%, p=0.948)$. Finally, the study published by Chen-Xu et al. [18] did not show either significant differences when comparing J-incision, L-incision, midline, subcostal, or transverse incisions $(12.6 \%$ vs. $17.6 \%$ vs. $16.5 \%$ vs. $6.8 \%$ vs. $14.2 \%, p=0.296)$. To summarize, according to the studies that included the type of incision as primary outcome, Mercedes and reversed $\mathrm{T}$ incision might be associated with a higher incidence of $\mathrm{IH}$, whilst J-shaped and ERSC incisions could involve a lower risk. With regard to closure methods, as shown in Table 2, there was also a considerable heterogeneity among the selected studies. Moreover, no comparisons between different closure methods were performed, except of in the publication by Kayashima et al. [34]. This study found a higher risk of $\mathrm{IH}$ in the event of using a running suture in comparison with an interrupted suture. Nevertheless, the fact that this study was only focused in cirrhotic patients, should also be beard in mind. Therefore, providing any insight regarding the ideal closure method in open HPB surgery is not viable as there is not enough evidence in the literature to give a solid recommendation.

\section{Discussion}

Although IH is not usually life-threatening complications outside of the setting of intestinal obstruction, they are a major source of morbidity and can significantly impair quality of life. This is all the more pertinent as survival has improved for many HPB cancers bringing a focus toward increasing patient's satisfaction. Therefore, more studies should centre the attention on value-based

Incisional Hernia in Hepato-PancreatoBiliary Surgery care, patient-centred and longer term outcomes. The increase in the rate of admissions and reoperations secondary to IH has also a significant economic impact and consequently a substantial cost burden for society [20,3739]. As stated before, most HPB operations are performed through lateral incisions. Unfortunately, high evidencebased data are lacking, and there are no consensus guidelines focused in the management of abdominal wall complications after non-midline laparotomies [11]. Furthermore, current evidence on LT recipients cannot be extrapolated either to all other HPB operations, due to confounding roles of immunosuppression or end-stage liver cirrhosis. Likewise, many HPB procedures are due to malignant disorders, and cancer itself as well as chemotherapy regimens have an impact on cicatrization too $[16$, 40].

The EHS guidelines recommend using imaging for the follow-up of IH prospective studies in order to increase the detection rate [10]. Computed tomography scan provides a more accurate diagnosis than ultrasound [41] although at least 2 years of follow-up are required [42]. In our review, most of the studies analysed, except of the published by D'Angelica et al. [32] and by Arslan et al. [35], used computed tomography scan or ultrasound. Median or mean follow-up was of at least 2 years. Therefore, data regarding the real incidence in the majority of the individual studies could be considered reliable. Even though the studies pooled an heterogenous population, we can presume that the incidence is considerable, as some studies report IH in up to one-third of their patients. Nonetheless, a higher number of comparable studies are needed in order to definitively establish this incidence rate.

Risk factors for IH development are divided into patient and surgical technique-related factors. Surgical technique factors include incision type, suturing material choice, wound tension, type of closure (running vs. interrupted), use of mesh, or surgeon's skills. Unlike patient risk factors, surgical technique factors depend entirely on the surgeon and can be optimized $[9,21,34]$. HPB procedures are frequently complex from the technical point of view and accordingly are conducted by senior surgeons, or senior trainees under supervision. However, abdominal wall closure is regularly performed by junior trainees, and often without adequate supervision. Obviously, an adequate technique is required in all cases, although identifying evidence-based risk factors might help to pay especial attention to those patient subsets. The benefit-risk ratio of measures such as mesh prophylaxis would also be higher in this group of high-risk patients. 
The fact that the different studies did not investigate the same risk factors was an issue. Furthermore, some studies established as exclusion criteria some of the risk factors demonstrated in the other studies, such as hemodynamic instability [30], re-laparotomy [34] or prior subcostal or supraumbilical laparotomy $[30,31]$. Therefore, in order to analyse all the risk factors identified in the different articles, more studies with broader inclusion criteria are needed. BMI was the most commonly identified risk factors [18, 32-34], a finding not unexpected considering other gastrointestinal operations as well as LT $[19,21,22]$. It is worth highlighting that another commonly identified risk factor was SSI. Whilst it was significant in the multivariate analysis of the studies published by Chen-Xu et al. [18], BravoSalva et al. [31], and D'Angelica et al. [32], Togo et al. [33] only identified wound infection as risk factor in the univariate analysis. These data regarding SSI are also reported in other publications [19]. Likewise, cirrhosis and ascites decompensation were also in the list of the most common risk factors [32-34]. It must be kept in mind that the heterogeneity among population of the studies also makes it difficult to draw conclusions in this specific matter. In fact, in studies including only cirrhotic patients [34], the probability of having ascites is much higher than in those where cirrhosis is uncommon such as in hepatectomies for colorectal metastases, in pancreatectomies or in other biliary procedures $[18,36]$. End-stage liver cirrhosis and ascites have also been associated to IH development in LT recipients [43]. Also, as expected, presenting a previously repaired $\mathrm{IH}$ was reported as a risk factor for developing a new $\mathrm{IH}$, although only by Nilsson et al. [36] and Bravo-Salva et al. [31]. Although a higher incidence of IH could be expected in patients with type $\mathrm{B}$ or $\mathrm{C}$ pancreatic fistula after pancreatic surgery, this association was not found in the multivariate analysis of any of the studies. Finally, whilst chemotherapy, which is common in HPB procedures such as hepatectomies for metastases and pancreatectomies for pancreatic cancer, was only identified as a significant risk factor by Nilsson et al. [36], Arslan et al. [35] also observed a non-significant trend between $\mathrm{IH}$ and postoperative chemotherapy. Wound healing impairment secondary to systemic or intraperitoneal chemotherapy have been reported as a risk factor for IH formation [44]; however, there was not a clear association seen in our review. More studies exclusively analysing the incidence of $\mathrm{IH}$ after liver resections for colorectal metastases should be designed to confirm the association of chemotherapy found by Nilsson et al. [36].

Collecting the current evidence regarding the prevention of IH after open HPB procedures was one of our main objectives. Unfortunately, to date there are no pub- lished randomised studies. As discussed earlier, mesh prophylaxis appears to be safe despite the high level of contamination commonly found in emergency surgery. Furthermore, mesh reinforcement also seemed to reduce the incidence of IH even when mesh group had more risk factors such as perioperative shock, reoperation, and surgical field contamination [31]. Similarly, in other types of laparotomies, there is increasing evidence that synthetic meshes are safe in contaminated wounds $[9,45,46]$. However, there is not enough evidence to determine yet the optimal type of mesh or its placement (onlay, sublay/ retrorectus, or underlay/preperitoneal) or if mesh should be used in all patients or only in high-risk subsets [42]. There are further 2 ongoing studies whose results may also contribute to current knowledge on the topic. The first study is the PRINC trial, based in LT recipients. The hypothesis of this RCT is that prevention with a fully absorbable mesh will reduce the incidence of IH after LT with minimal risks for complications [47]. With regard to non-LT patients, another ongoing Polish trial aims to evaluate risk factors for development of $\mathrm{IH}$ in transverse epigastric incisions in patients after oncologic surgery.

Regarding the closure method, a Cochrane review published in 2017 [25] did not find high-quality evidence to determine the best type of suture material or technique. Only monofilament was shown to reduce the risk of IH when compared to polyfilament sutures. In our review, Kayashima et al. [34] did show a possible association between closure method and risk of IH formation. Several studies have demonstrated a benefit using a small bites technique for fascial closure in reducing $\mathrm{IH}$ in midline laparotomies Theoretically, this may apply subcostal incisions, but this has not been demonstrated [20,30, 48, 49]. Finally, with regard to incision type, a multitude of incisions have been described. According to our review [32, 33], Mercedes and reversed T incisions should be avoided and J-shaped or ERSC should be the preferred. Ischemia in the trifurcation point from the midline fascia probably plays a role in both Mercedes and reversed $\mathrm{T}$ incisions. Whilst it might me argued that Kayashima et al. [34] and Nilsson et al. [36] did not find differences according to the type of incision, this variable was not part of their primary outcome and the number of J-shape or ERSC in both studies was significantly higher. We believe this might have had an influence in their results. In fact, other authors also reported similar recommendations in terms of incision type for both LT and liver resections [21, 35, 50].

The main limitation of our review was the lack of comparative studies. Our assessment is also limited by the heterogeneity of the available studies, including differences 
in patients' types, procedures, follow-up, closure methods, and exclusion criteria. However, this review covers this important topic exclusively for open HPB procedures.

\section{Conclusion}

In conclusion, this review demonstrates that $\mathrm{IH}$ after open HPB surgery is a prevalent issue. Whilst many important risk factors are patient-related, surgical factors such as incision type are also significant and the authors suggest that alternatives to Mercedes and revered T incisions should be considered where possible. RCTs or at least observational comparative studies with broader inclusion criteria, homogeneous group of patients/surgical procedures and consistent outcome measures to analyse the potential benefit and safety of prophylactic meshes are needed.

\section{Acknowledgments}

The authors wish to thank Ms. Noemi Aluja (medical librarian) for her valuable contribution in the search strategy.

\section{Statement of Ethics}

This study complies with the guidelines for human studies. The research was conducted ethically in accordance with the World Medical Association Declaration of Helsinki. As a systematic review of the literature, the article is exempt from Ethical Committee approval.

\section{Conflict of Interest Statement}

All named authors hereby declare that they have no conflict of interest to disclose.

\section{Funding Sources}

This research did not receive any specific grant from funding agencies in the public, commercial, or not-for-profit sectors.

\section{Author Contributions}

The followings are the authors' contributions: conception and study design: R. Memba, R. Jorba, O. Morató, C. Olona, D.B. O'Connor, and M.C. Pavel; screening and selection of papers: R. Memba, O. Morató, R. Jorba, and E. Padilla; interpretation of data: R. Memba, O. Morató, R. Jorba, E. Estalella, E. Llàcer-Millán, M. Achalandabaso, and E. Julià; writing original draft: R. Memba; critical review of the manuscript: O. Morató, E. Estalella, M.C. Pavel, E. Llàcer-Millán, M. Achalandabaso, E. Julià, E. Padilla, C. Olona, D.B. O'Connor, and R. Jorba; final approval: R. Memba, R. Jorba, D.B. O’Connor, O. Morató, C. Olona, E. Estalella, M.C. Pavel, E. Llàcer-Millán, M. Achalandabaso, E. Julià, and E. Padilla.

\section{Data Availability Statement}

All data generated or analysed during this study are included in this article and/or its online supplementary material. Further enquiries can be directed to the corresponding author.

\section{References}

1 Ejaz A, Sachs T, He J, Spolverato G, Hirose K, Ahuja N, et al. A comparison of open and minimally invasive surgery for hepatic and pancreatic resections using the Nationwide Inpatient Sample. Surgery. 2014 Sep;156(3):538-47.

2 Zureikat AH, Borrebach J, Pitt HA, McGill D, Hogg ME, Thompson V, et al. Minimally invasive hepatopancreatobiliary surgery in North America: an ACS-NSQIP analysis of predictors of conversion for laparoscopic and robotic pancreatectomy and hepatectomy. HPB. 2017 Jul;19(7):595-602.

3 Guerra F, Guadagni S, Pesi B, Furbetta N, Di Franco G, Palmeri M, et al. Outcomes of robotic liver resections for colorectal liver metastases. A multi-institutional analysis of minimally invasive ultrasound-guided robotic surgery. Surg Oncol. 2019 Mar;28:14-8.

4 Rosok BI, de Rooij T, van Hilst J, Diener MK, Allen PJ, Vollmer CM, et al. Minimally invasive distal pancreatectomy. HPB. 2017 Mar; 19(3):205-14.
5 Souche R, Herrero A, Bourel G, Chauvat J, Pirlet I, Guillon F, et al. Robotic versus laparoscopic distal pancreatectomy: a French prospective single-center experience and cost-effectiveness analysis. Surg Endosc. 2018 Aug; 32(8):3562-9.

6 de Rooij T, Besselink MG, Shamali A, Butturini G, Busch OR, Edwin B, et al. Pan-European survey on the implementation of minimally invasive pancreatic surgery with emphasis on cancer. HPB. 2016 Feb;18(2):170-6.

7 Doula C, Kostakis ID, Damaskos C, Machairas N, Vardakostas DV, Feretis T, et al. Comparison between minimally invasive and open pancreaticoduodenectomy: a systematic review. Surg Laparosc Endosc Percutan Tech. $2016 \mathrm{Feb} ; 26(1): 6-16$

8 Zhang YH, Zhang CW, Hu ZM, Hong DF. Pancreatic cancer: open or minimally invasive surgery? World J Gastroenterol. 2016 Aug 28;22(32):7301-10.
9 Alli VV, Zhang J, Telem DA. Impact of incisional hernia development following abdominal operations on total healthcare cost. Surg Endosc. 2018 May;32(5):2381-6.

10 Muysoms FE, Miserez M, Berrevoet F, Campanelli G, Champault GG, Chelala E, et al. Classification of primary and incisional abdominal wall hernias. Hernia. 2009 Aug; 13(4):407-14.

11 Stumpf M, Conze J, Prescher A, Junge K, Krones CJ, Klinge U, et al. The lateral incisional hernia: anatomical considerations for a standardized retromuscular sublay repair. Hernia. 2009 Jun;13(3):293-7.

12 Veyrie N, Poghosyan T, Corigliano N, Canard G, Servajean S, Bouillot JL. Lateral incisional hernia repair by the retromuscular approach with polyester standard mesh: topographic considerations and long-term follow-up of 61 consecutive patients. World J Surg. 2013 Mar; 37(3):538-44. 
13 Gauduchon L, Sabbagh C, Mauvais F, Regimbeau JM. Technical aspects of right subcostal incisional hernia repair. J Visc Surg. 2014 Oct; 151(5):393-401.

14 Fikatas P, Schoening W, Lee JE, Chopra SS, Seehofer D, Guckelberger O, et al. Incidence, risk factors and management of incisional hernia in a high volume liver transplant center. Ann Transplant. 2013 May 16;18:223-30.

15 de Goede B, Eker HH, Klitsie PJ, van Kempen BJ, Polak WG, Hop WC, et al. Incisional hernia after liver transplantation: risk factors and health-related quality of life. Clin Transplant. 2014 Jul;28(7):829-36.

16 Lam HD, Vanlander A, Berrevoet F. A comparative outcome analysis of incisional hernia repair in patients who underwent liver transplantation vs. those that underwent hepatopancreaticobiliary surgery using the EHS guidelines as a means of comparison. Clin Transplant. 2016 Mar;30(3):226-32.

17 Lee JS, Kim JM, Kim KS, Choi GS, Joh JW, Lee SK. Predictors of incisional hernia in adult liver transplant recipients. Hernia. 2019 Feb; 23(1):61-5.

18 Chen-Xu J, Bessa-Melo R, Graça L, CostaMaia J. Incisional hernia in hepatobiliary and pancreatic surgery: incidence and risk factors. Hernia. 2019 Feb;23(1):67-79.

19 Itatsu K, Yokoyama Y, Sugawara G, Kubota $\mathrm{H}$, Tojima Y, Kurumiya Y, et al. Incidence of and risk factors for incisional hernia after abdominal surgery. Br J Surg. 2014 Oct;101(11): 1439-47.

20 Baucom RB, Ousley J, Beveridge GB, Phillips SE, Pierce RA, Holzman MD, et al. Cancer survivorship: defining the incidence of incisional hernia after resection for intra-abdominal malignancy. Ann Surg Oncol. 2016 Dec; 23(Suppl 5):764-71.

21 Garmpis N, Spartalis E, Schizas D, Patsouras D, Damaskos C, Spartalis M, et al. Incisional hernias post liver transplantation: current evidence of epidemiology, risk factors and laparoscopic versus open repair. A review of the literature. In Vivo. 2019 Jul-Aug;33(4):1059-66.

22 Howard R, Thompson M, Fan Z, Englesbe M, Dimick JB, Telem DA. Costs associated with modifiable risk factors in ventral and incisional hernia repair. JAMA Netw Open. 2019 Nov 1;2(11):e1916330.

23 Kohler A, Lavanchy JL, Lenoir U, Kurmann A, Candinas D, Beldi G. Effectiveness of prophylactic intraperitoneal mesh implantation for prevention of incisional hernia in patients undergoing open abdominal surgery: a randomized clinical trial. JAMA Surg. 2019 Feb 1;154(2):109-15

24 Borab ZM, Shakir S, Lanni MA, Tecce MG, MacDonald J, Hope WW, et al. Does prophylactic mesh placement in elective, midline laparotomy reduce the incidence of incisional hernia? A systematic review and meta-analysis. Surgery. 2017 Apr;161(4):1149-63.

25 Patel SV, Paskar DD, Nelson RL, Vedula SS, Steele SR. Closure methods for laparotomy incisions for preventing incisional hernias and other wound complications. Cochrane Database Syst Rev. 2017 Nov 3;11:CD005661.

26 Wang XC, Zhang D, Yang ZX, Gan JX, Yin LN. Mesh reinforcement for the prevention of incisional hernia formation: a systematic review and meta-analysis of randomized controlled trials. J Surg Res. 2017 Mar;209:17-29.

27 Shamseer L, Moher D, Clarke M, Ghersi D, Liberati A, Petticrew M, et al. Preferred reporting items for systematic review and metaanalysis protocols (PRISMA-P) 2015: elaboration and explanation. BMJ. 2015 Jan 2;350: g7647.

28 Shea BJ, Grimshaw JM, Wells GA, Boers M, Andersson N, Hamel C, et al. Development of AMSTAR: a measurement tool to assess the methodological quality of systematic reviews. BMC Med Res Methodol. 2007 Feb 15;7:10.

29 Stang A. Critical evaluation of the NewcastleOttawa scale for the assessment of the quality of nonrandomized studies in meta-analyses. Eur J Epidemiol. 2010 Sep;25(9):603-5.

30 Blazquez Hernando LA, Garcia-Urena MA, Lopez-Monclus J, Hernandez SG, Valle de Lersundi AR, Cidoncha AC, et al. Prophylactic mesh can be used safely in the prevention of incisional hernia after bilateral subcostal laparotomies. Surgery. 2016 Nov; 160(5):1358-66.

31 Bravo-Salva A, Gonzalez-Castillo AM, Vela-Polanco FF, Membrilla-Fernandez E, VilaDomenech J, Pera-Roman M, et al. Incidence of incisional hernia after emergency subcostal unilateral laparotomy: does augmentation prophylaxis play a role? World J Surg. 2020;44(3):741-8

32 D'Angelica M, Maddineni S, Fong Y, Martin RC, Cohen MS, Ben-Porat L, et al. Optimal abdominal incision for partial hepatectomy: increased late complications with Mercedestype incisions compared to extended right subcostal incisions. World J Surg. 2006 Mar; 30(3):410-8.

33 Togo S, Nagano Y, Masumoto C, Takakura H, Matsuo K, Takeda K, et al. Outcome of and risk factors for incisional hernia after partial hepatectomy. J Gastrointest Surg. 2008 Jun; 12(6):1115-20

34 Kayashima H, Maeda T, Harada N, Masuda T, Guntani A, Ito S, et al. Risk factors for incisional hernia after hepatic resection for hepatocellular carcinoma in patients with liver cirrhosis. Surgery. 2015 Dec;158(6):1669-75.

35 Arslan MK, Aydin C, Topaloglu S, Calik A, Tomas K, Karabulut E. Incidence of and risk factors for incisional hernia after liver surgery performed with a J-shaped right subcostal incision. Am Surg. 2017 Feb 1;83(2):e49-53.

36 Nilsson JH, Strandberg Holka P, Sturesson C. Incisional hernia after open resections for colorectal liver metastases - incidence and risk factors. HPB. 2016 May;18(5):436-41.

37 Zhang JD, Wang SJ, Lv C, Xing X. Treatment for long-term poorly closed incisions after hepatobiliary surgery. Hepatobiliary Pancreat Dis Int. 2008 Jun;7(3):280-3.

38 van Ramshorst GH, Eker HH, Hop WC, Jeekel J, Lange JF. Impact of incisional hernia on health-related quality of life and body im- age: a prospective cohort study. Am J Surg. 2012 Aug;204(2):144-50.

39 Fischer JP, Basta MN, Mirzabeigi MN, Bauder AR, Fox JP, Drebin JA, et al. A risk model and cost analysis of incisional hernia after elective, abdominal surgery based upon 12,373 cases: the case for targeted prophylactic intervention. Ann Surg. 2016 May;263(5):1010-7.

40 Davey S, Rajaretnem N, Harji D, Rees J, Messenger D, Smart NJ, et al. Incisional hernia formation in hepatobiliary surgery using transverse and hybrid incisions: a systematic review and meta-analysis. Ann R Coll Surg Engl. 2020 Nov; 102(9):663-71.

41 Kroese LF, Sneiders D, Kleinrensink GJ, Muysoms F, Lange JF. Comparing different modalities for the diagnosis of incisional hernia: a systematic review. Hernia. 2018 Apr;22(2):229-42.

42 Caro-Tarrago A, Olona C, Millán M, Olona M, Espina B, Jorba R. Long-term results of a prospective randomized trial of midline laparotomy closure with onlay mesh. Hernia. 2019 Apr;23(2):335-40.

43 Ayvazoglu Soy EH, Kirnap M, Yildirim S, Moray G, Haberal M. Incisional hernia after liver transplant. Exp Clin Transplant. 2017 Feb;15(Suppl 1):185-9.

44 Tuttle TM, Huang JL, Kizy S, Altman AM, Nalluri H, Marmor S, et al. Incidence and predictors of incisional hernia after cytoreductive surgery and hyperthermic intraperitoneal chemotherapy. Int J Hyperthermia. 2019; 36(1):812-6.

45 Payne R, Aldwinckle J, Ward S. Meta-analysis of randomised trials comparing the use of prophylactic mesh to standard midline closure in the reduction of incisional herniae. Hernia. 2017 Dec;21(6):843-53.

46 Pandey H, Thakur DS, Somashekar U, Kothari R, Agarwal P, Sharma D. Use of polypropylene mesh in contaminated and dirty strangulated hernias: short-term results. Hernia. 2018 Dec;22(6): 1045-50

47 Kniepeiss D, Waha JE, Auer T, Berghold A, Schemmer P. Prevention of incisional hernia after liver transplantation (PRINC trial): study protocol for a randomized controlled trial. Trials. 2019 Jun 20;20(1):371.

48 Deerenberg EB, Harlaar JJ, Steyerberg EW, Lont HE, van Doorn HC, Heisterkamp J, et al. Small bites versus large bites for closure of abdominal midline incisions (STITCH): a double-blind, multicentre, randomised controlled trial. Lancet. 2015 Sep 26;386(10000): 1254-60.

49 de Vries HS, Verhaak T, van Boxtel TH, van den Heuvel W, Teixeira MB, Heisterkamp J, et al. Implementation of the small bites closure of abdominal midline incisions in clinical practice is correlated with a reduction in surgical site infections. Hernia. 2020 Aug; 24(4):839-43.

50 Heisterkamp J, Marsman HA, Eker H, Metselaar HJ, Tilanus HW, Kazemier G. A J-shaped subcostal incision reduces the incidence of abdominal wall complications in liver transplantation. Liver Transpl. 2008 Nov;14(11):1655-8. 